\title{
Separate Vertical Wiring for the Fixation of Comminuted Fractures of the Inferior Pole of the Patella
}

\author{
Hyung Keun Song, ${ }^{1}$ Je Hyun Yoo, ${ }^{2}$ Young Soo Byun, ${ }^{3}$ and Kyu Hyun Yang ${ }^{4}$ \\ 'Department of Orthopaedic Surgery, Ajou University School of Medicine, Suwon; \\ 2Department of Orthopaedic Surgery, Hallym University Sacred Heart Hospital, Anyang; \\ ${ }^{3}$ Department of Orthopaedic Surgery, Daegu Fatima Hospital, Daegu; \\ ${ }^{4}$ Department of Orthopaedic Surgery, Gangnam Severance Hospital, Yonsei University College of Medicine, Seoul, Korea.
}

Received: January 28, 2014

Accepted: February 28, 2014

Corresponding author: Dr. Kyu Hyun Yang,

Department of Orthopaedic Surgery,

Gangnam Severance Hospital,

211 Eonju-ro, Gangnam-gu,

Seoul 135-720, Korea.

Tel: 82-2-2019-3414, Fax: 82-2-573-5393

E-mail: kyang@yuhs.ac

- The authors have no financial conflicts of interest.

Purpose: Among patients over 50 years of age, separate vertical wiring alone may be insufficient for fixation of fractures of the inferior pole of the patella. Therefore, mechanical and clinical studies were performed in patients over the age of 50 to test the strength of augmentation of separate vertical wiring with cerclage wire (i.e., combined technique). Materials and Methods: Multiple osteotomies were performed to create four-part fractures in the inferior poles of eight pairs of cadaveric patellae. One patella from each pair was fixed with the separate wiring technique, while the other patella was fixed with a combined technique. The ultimate load to failure and stiffness of the fixation were subsequently measured. In a clinical study of 21 patients (average age of 64 years), comminuted fractures of the inferior pole of the patellae were treated using the combined technique. Operative parameters were recorded from which post-operative outcomes were evaluated. Results: For cadaveric patellae, whose mean age was 69 years, the mean ultimate loads to failure for the separate vertical wiring technique and the combined technique were $216.4 \pm 72.4 \mathrm{~N}$ and $324.9 \pm 50.6 \mathrm{~N}$, respectively $(p=0.012)$. The mean stiffness for the separate vertical wiring technique and the combined technique was $241.1 \pm 68.5 \mathrm{~N} /$ $\mathrm{mm}$ and $340.8 \pm 45.3 \mathrm{~N} / \mathrm{mm}$, respectively ( $p=0.012$ ). In the clinical study, the mean clinical score at final follow-up was 28.1 points. Conclusion: Augmentation of separate vertical wiring with cerclage wire provides enough strength for protected early exercise of the knee joint and uneventful healing.

Key Words: Patella, inferior pole, vertical wiring, cerclage wiring

\section{INTRODUCTION}

\section{(C) Copyright: \\ Yonsei University College of Medicine 2014}

This is an Open Access article distributed under the terms of the Creative Commons Attribution NonCommercial License (http://creativecommons.org/ licenses/by-nc/3.0) which permits unrestricted noncommercial use, distribution, and reproduction in any medium, provided the original work is properly cited.
Patellar fractures account for approximately $1 \%$ of all fractures, and approximately $5 \%$ of these patellar fractures involve the inferior pole. ${ }^{1,2}$ Displaced inferior pole fragments are usually comminuted and too small to withstand anatomical reduction and stable internal fixation. Various methods have been introduced to fix these fractures, including tension band wiring, ${ }^{2}$ separate vertical wiring, ${ }^{3}$ basket plate, ${ }^{4}$ wiring through cannulated screws, ${ }^{5}$ and partial patellectomy, ${ }^{2}$ and each of these 
techniques has its own advantages and disadvantages. ${ }^{6,7}$ The major advantage of the separate vertical wiring technique is that tightening of the vertical wires can reduce the number of fragments with minimal soft tissue handling. Additionally, these fragments generally remain in a reduced position when the knee is in motion. However, the holding power of separate vertical wires is not strong enough for early active exercise due to the inherent weakness of the comminuted small fragments. In a previous report on separate vertical wiring, two of 25 patients experienced complications due to the weak holding power of the wiring technique. ${ }^{3}$ In these two patients, who were 57 and 60 years old, the fragments were disrupted after a fall, causing the wire to loosen, necessitating reoperation or cast immobilization. In order to strengthen the holding power of the separate vertical wiring technique in patients over 50 years, we performed mechanical and clinical studies to test whether augmentation of separate vertical wiring with cerclage wire in a combined technique could provide enough strength for early exercise of the knee joint.

\section{MATERIALS AND METHODS}

\section{Biomechanical study}

Separate vertical wiring and mechanical testing were performed as previously described by Yang and Byun. ${ }^{3}$ Specifically, eight pairs of embalmed knees from cadavers with a mean age of 69 years (range: 55 to 80 years) were used to model acute comminuted fractures of the inferior pole of

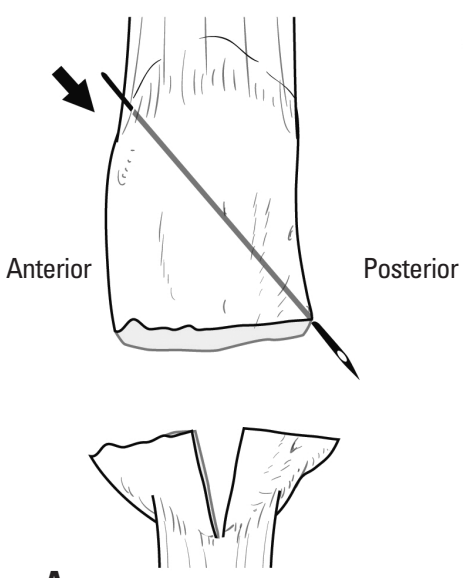

\section{A}

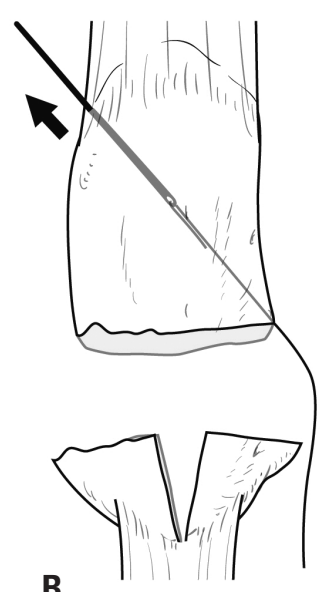

B

Fig. 1. Separate vertical wiring technique (lateral view of the patella). (A) A number one Steinmann pin with a small hole at its end was inserted vertically from the antero-superior aspect of the patella to the most posterior aspect of the transverse osteotomy; (B) a 0.75 -mm diameter wire suture was passed through the hole in the Steinmann pin until the tip emerged from the osteotomy site and the Steinmann pin was then withdrawn with the wire; (C) the distal end of the wire was passed through the patellar tendon as close as possible to the bone from the posterior aspect of the two bone fragments; and (D) the distal end of the wire was then pulled anteriorly, twisted, and tightened with the proximal end at the anterosuperior aspect of the patella. This procedure successfully reduced the number of fragments. the patella. The patellae, patellar tendons, and tibial tuberosities were isolated and removed. A transverse osteotomy was performed at the inferior margin of the articular surface of the patella using a micro oscillating saw (6 mm cutting width, 0.015 " blade thickness) starting from the articular side perpendicular to the bone. A coronal osteotomy of the inferior pole was performed along the long axis toward the tip, and a sagittal osteotomy was performed from the center of each fragment. Osteotomy was performed to mimic a comminuted fracture dividing the inferior pole of the patella into four parts. The resulting patellar fracture was then fixed by separate vertical wiring or, for the contralateral patella, with a combined technique of separate vertical wiring with cerclage wire.

Separate vertical wiring was performed in the following sequence (Fig. 1): 1) A number one Steinmann pin with a small hole at its end was inserted vertically from the anterosuperior aspect of the patella to the most posterior aspect of the transverse osteotomy (Fig. 1A); 2) a 0.75-mm diameter wire suture was passed through the hole in the Steinmann pin until the tip emerged from the osteotomy site and the Steinmann pin was then withdrawn with the wire (Fig. 1B); 3 ) the distal end of the wire was passed through the patellar tendon as close as possible to the bone from the posterior aspect of the two bone fragments (Fig. 1C); and 4) the distal end of the wire was then pulled anteriorly, twisted, and tightened with the proximal end at the anterosuperior aspect of the patella (Fig. 1D). This procedure successfully reduced the number of fragments.

The specimens were mounted and loaded with uniaxial

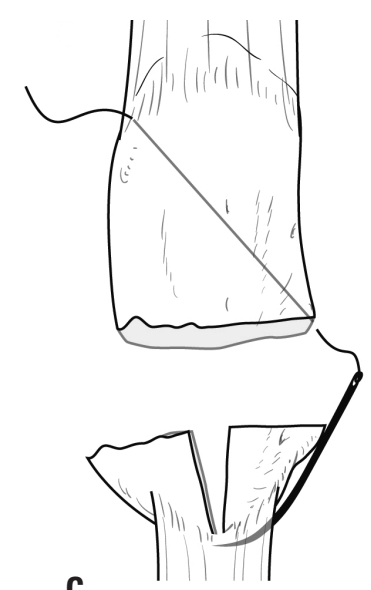

C

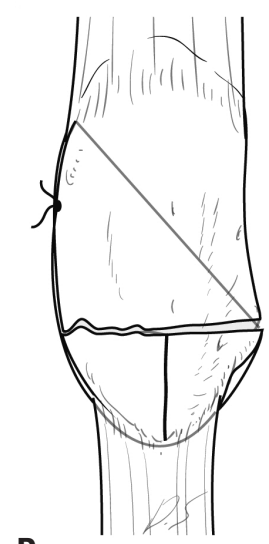

D 
tension using an Instron machine (Instron model 6022; Instron Co., Canton, MA, USA). The patella and tibial tuberosities were fixed to the proximal and distal clamps, respectively, using wires. The tensile velocity was $1 \mathrm{~mm} / \mathrm{min}$. The ultimate load to failure and stiffness were defined as dissociation of the area of the osteotomy by $3 \mathrm{~mm}$ or more, or the fixed metal wire being destroyed. Cases were excluded from this study if separation of the specimen from the clamp fixation occurred before dissociation of the area of the osteotomy.

The ultimate load to failure and stiffness of each fixation technique were analyzed using the Wilcoxon Signed Rank test and Spearman's rank correlation coefficient test with a significance level of $p<0.05$.

\section{Clinical study}

From March 2005 to September 2012, 24 patients $\geq 50$ years old were seen at our hospital for displaced comminuted fractures of the inferior pole of the patella. Patients followed for less than 12 months after fracture fixation were excluded from this analysis, which resulted in a final cohort of 21 patients.

Depending on the level of damage to the patella, the skin was cut in a longitudinal or horizontal direction after general or spinal anesthesia. Separate vertical wiring was performed after debridement of the injured soft tissues and evacuation of hematoma (Fig. 1). The number and location of the crushed bony fragments of the inferior pole of the patella determined the number and location of separate vertical wiring. Vicryl 1-0 sutures were placed in the tissue neighboring the bony fragment for stabilization. Cerclage wiring (1.0 mm diameter) was performed close to the patella. A safety check for early knee range of motion (ROM) was performed before wound closure. Two days after surgery, continuous passive ROM exercise and quadriceps strengthening exercises were performed. One week after surgery, active ROM and partial weight bearing with a crutch or walker was encouraged. To prevent sudden knee flexion, the knee joint was protected for 1 month by a brace with flexion limited from $0^{\circ}$ to $90^{\circ}$. Anteroposterior and lateral views of the knee joint obtained during follow-up were used to assess bony union based on the time when the fracture line disappeared. At the time of the final outpatient checkup, functional evaluation of the knee joint was conducted by the method used by Böstman, et al. ${ }^{8}$ (Table 1).

The study was approved by our Institutional Review Board (IRB No: 3-2011-0099).

\section{RESULTS}

\section{Biomechanical study}

No dissociation was found in the area of the upper and lower clamp fixation, but separation occurred in all osteotomy areas. The mean ultimate load to failure of the separate vertical wiring technique and the combined technique was $216.4 \pm 72.4 \mathrm{~N}$ (range: 131.7 to $365.2 \mathrm{~N}$ ) and $324.9 \pm 50.6 \mathrm{~N}$ (range: 264.8 to $423.8 \mathrm{~N}$ ), respectively ( $p=0.012$ ) (Fig. 2).

Table 1. Details of the Clinical Grading Scale of Böstman, et al. ${ }^{8}$

\begin{tabular}{|c|c|}
\hline Variable & Points \\
\hline \multicolumn{2}{|l|}{ Range of movement (ROM) } \\
\hline $\begin{array}{l}\text { Full extension and the ROM }>120^{\circ} \text { or } \\
\text { within } 10^{\circ} \text { of the normal side }\end{array}$ & 6 \\
\hline Full extension, movement $90^{\circ}$ to $120^{\circ}$ & 3 \\
\hline \multicolumn{2}{|l|}{ Pain } \\
\hline None or minimal on exertion & 6 \\
\hline Moderate on exertion & 3 \\
\hline In daily activity & 0 \\
\hline \multicolumn{2}{|l|}{ Work } \\
\hline Original job & 4 \\
\hline Different job & 2 \\
\hline Cannot work & 0 \\
\hline \multicolumn{2}{|l|}{$\begin{array}{l}\text { Atrophy, difference of circumference of } \\
\text { thigh } 10 \mathrm{~cm} \text { proximal to the patella }\end{array}$} \\
\hline$<12 \mathrm{~mm}$ & 4 \\
\hline 12 to $25 \mathrm{~mm}$ & 2 \\
\hline$>25 \mathrm{~mm}$ & 0 \\
\hline \multicolumn{2}{|l|}{ Assistance in walking } \\
\hline None & 4 \\
\hline Cane part of the time & 2 \\
\hline Cane all the time & 0 \\
\hline \multicolumn{2}{|l|}{ Effusion } \\
\hline None & 2 \\
\hline Reported to be present & 1 \\
\hline Present & 0 \\
\hline \multicolumn{2}{|l|}{ Giving way } \\
\hline None & 2 \\
\hline Sometimes & 1 \\
\hline In daily life & 0 \\
\hline \multicolumn{2}{|l|}{ Stair-climbing } \\
\hline Normal & 2 \\
\hline Disturbing & 1 \\
\hline Disabling & 0 \\
\hline \multicolumn{2}{|l|}{ Total score } \\
\hline Excellent & 30 to 28 \\
\hline Good & 27 to 20 \\
\hline Unsatisfactory & $<20$ \\
\hline
\end{tabular}



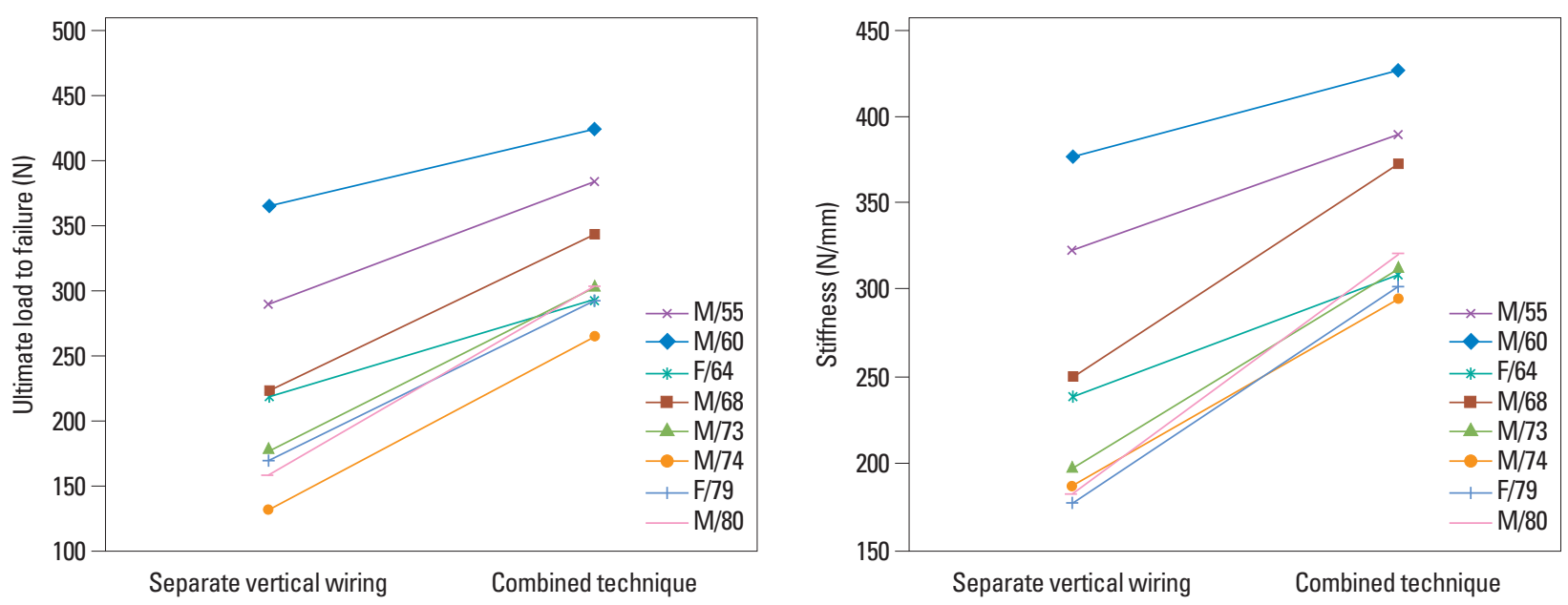

Fig. 2. The ultimate load to failure and stiffness for the separate vertical wiring technique and for the combined technique.
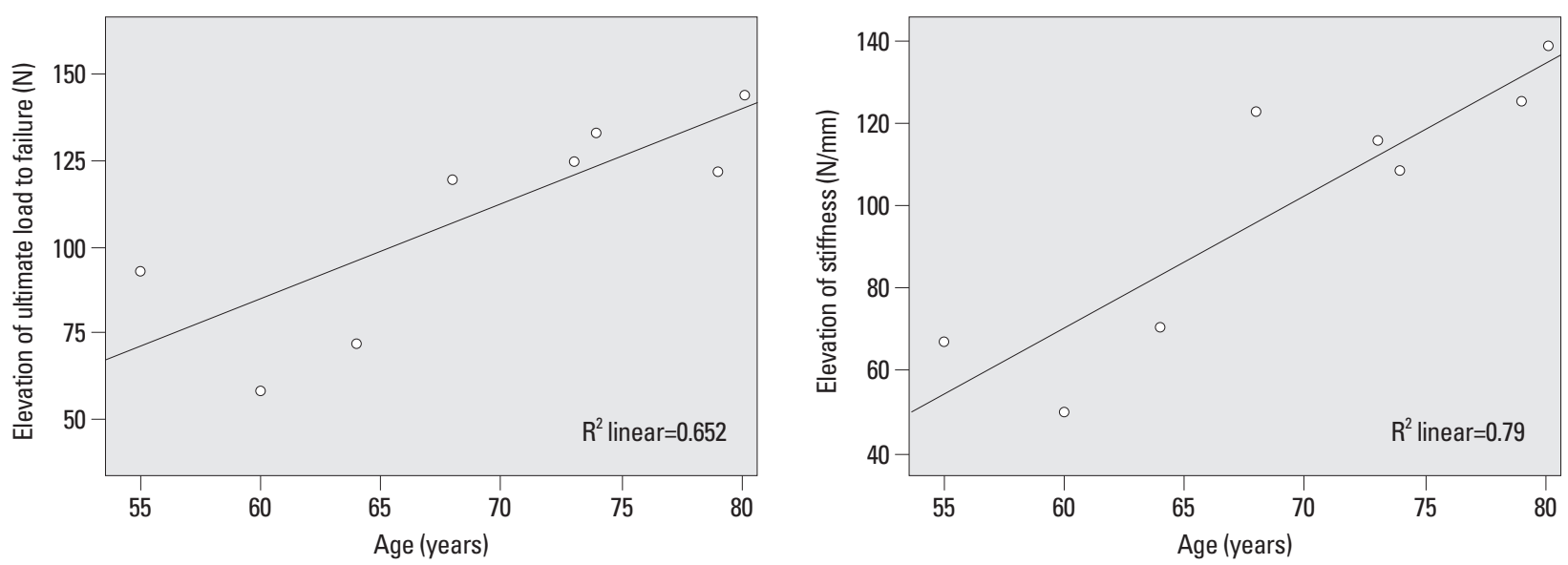

Fig. 3. The augmentation effect of cerclage wiring is stronger the higher the age.

The mean stiffness of the separate vertical wiring technique and the combined technique was $241.1 \pm 68.5 \mathrm{~N} / \mathrm{mm}$ (range: 176.3 to $376.1 \mathrm{~N} / \mathrm{mm}$ ) and $340.8 \pm 45.3 \mathrm{~N} / \mathrm{mm}$ (range: 295.2 to $426.1 \mathrm{~N} / \mathrm{mm}$ ), respectively ( $p=0.012$ ) (Fig. 2). The augmentation effect of cerclage wiring was unique to those specimens of older age: ultimate load to failure [r: 0.857 $(p=0.007)]$ and stiffness [r: $0.881(p=0.004)]$ (Fig. 3).

\section{Clinical study}

Among the 21 patients enrolled in this study, 10 were males. The mean age was 64 years (range: 50 to 90 years), and the average length of follow-up was 25 months (range: 12 to 57 months) (Table 2). The average operative time was 72.1 minutes, and bony union was obtained after an average of 8 weeks (range: 6 to 10 weeks) (Fig. 4). For both a 53-yearold female patient and a 90 -year-old male patient, a fracture was found in the body of the patella, so additional fixation was performed using Kirschner wires or screws. Breakage of the cerclage wire occurred in four patients: 3 months af- ter surgery in a 57-year-old female patient and in a 58-yearold male patient, 5 months after surgery in 51-year-old male patient, and 16 months after surgery in a 70-year-old female patient. However, there was no loosening of the separate vertical wire, and no patient complained of any discomfort around the broken wire or pain when moving the joint. After further observation, no patient developed posttraumatic osteoarthritis, progression of existing arthritis, or inflammation after surgery. At final follow-up, the average ROM was $138^{\circ}$ (range: $120-145^{\circ}$ ), and the flexion lag compared with the contralateral healthy lag averaged $3^{\circ}$ (range: $0-20^{\circ}$ ). All patients exhibited full knee extension. No patellar baja was observed on any radiographic evaluation (mean angle: $23.1^{\circ}$; range: $19.7-27.6^{\circ}$ ), and measurement of the clinical results averaged 28.1 points (range: 26-30). Of note, a 65 -year-old female patient had sustained a patellar fracture 13 years previously and was treated at that time with the tension band wiring technique. This patient lost the final $20^{\circ}$ of knee flexion after bony union. Eight years after 
Table 2. Details on Cases

\begin{tabular}{|c|c|c|c|c|c|c|c|c|c|}
\hline Case & $\begin{array}{l}\text { Age }(\mathrm{yrs}) / \\
\text { gender }\end{array}$ & $\begin{array}{l}\text { Number } \\
\text { of wires }\end{array}$ & $\begin{array}{l}\text { Time to } \\
\text { union } \\
\text { (wks) }\end{array}$ & $\begin{array}{l}\text { Follow-up } \\
\text { (months) }\end{array}$ & $\begin{array}{l}\text { Range of } \\
\text { motion at final } \\
\text { follow up }\end{array}$ & $\begin{array}{c}\text { Flexion lag } \\
\text { versus } \\
\text { contralateral } \\
\text { healthy leg }\end{array}$ & Complication & Result $^{\dagger}$ & $\begin{array}{l}\text { Removal } \\
\text { of wire }\end{array}$ \\
\hline 1 & $90 / \mathrm{M}$ & 3 & 10 & 27 & $0-140$ & 0 & None & 27 & \\
\hline 2 & $57 / \mathrm{M}$ & 3 & 7 & 55 & $0-145$ & 0 & None & 27 & ○ \\
\hline 3 & $65 / F$ & 3 & 8 & 57 & $0-120$ & 20 & None & 28 & \\
\hline 4 & $52 / \mathrm{M}$ & 3 & 7 & 35 & $0-145$ & 0 & None & 28 & ○ \\
\hline $5^{*}$ & $53 / \mathrm{F}$ & 3 & 8 & 32 & $0-145$ & 0 & None & 30 & \\
\hline 6 & $57 / \mathrm{F}$ & 3 & 6 & 32 & $0-140$ & 0 & $\begin{array}{l}\text { Cerclage wire breakage } \\
\text { (3 months) }\end{array}$ & 30 & \\
\hline $7 *$ & $90 / \mathrm{M}$ & 2 & 9 & 22 & $0-145$ & 0 & None & 27 & \\
\hline 8 & $70 / \mathrm{M}$ & 3 & 7 & 26 & $0-135$ & 5 & None & 26 & \\
\hline 9 & $70 / F$ & 3 & 7 & 26 & $0-140$ & 0 & $\begin{array}{l}\text { Cerclage wire breakage } \\
\text { (16 months) }\end{array}$ & 28 & \\
\hline 10 & $63 / \mathrm{M}$ & 3 & 6 & 22 & $0-135$ & 5 & None & 28 & \\
\hline 11 & $51 / \mathrm{M}$ & 3 & 7 & 23 & $0-140$ & 0 & None & 30 & $\circ$ \\
\hline 12 & $50 / \mathrm{M}$ & 3 & 8 & 20 & $0-140$ & 0 & $\begin{array}{l}\text { Cerclage wire breakage } \\
\text { ( } 5 \text { months })\end{array}$ & 28 & ० \\
\hline 13 & $73 / \mathrm{M}$ & 3 & 10 & 18 & $0-130$ & 10 & None & 26 & \\
\hline 14 & $51 / \mathrm{M}$ & 3 & 6 & 24 & $0-140$ & 0 & None & 29 & \\
\hline 15 & $67 / \mathrm{F}$ & 3 & 9 & 22 & $0-130$ & 15 & None & 28 & \\
\hline 16 & $56 / \mathrm{F}$ & 3 & 7 & 21 & $0-140$ & 0 & None & 30 & ० \\
\hline 17 & $57 / F$ & 3 & 8 & 23 & $0-140$ & 0 & None & 29 & \\
\hline 18 & $73 / \mathrm{F}$ & 3 & 9 & 12 & $0-135$ & 10 & None & 27 & \\
\hline 19 & $62 / \mathrm{M}$ & 3 & 8 & 13 & $0-140$ & 0 & None & 29 & ○ \\
\hline 20 & $58 / \mathrm{M}$ & 3 & 8 & 12 & $0-140$ & 0 & $\begin{array}{l}\text { Cerclage wire breakage } \\
\qquad(3 \text { months })\end{array}$ & 28 & ○ \\
\hline 21 & $78 / \mathrm{F}$ & 3 & 10 & 12 & $0-140$ & 0 & None & 27 & \\
\hline
\end{tabular}

${ }^{*}$ Combined fixation with K-wire or screw.

${ }^{\dagger}$ The results are based on the grading scale of Böstman, et al. ${ }^{8}$ at the latest follow-up.
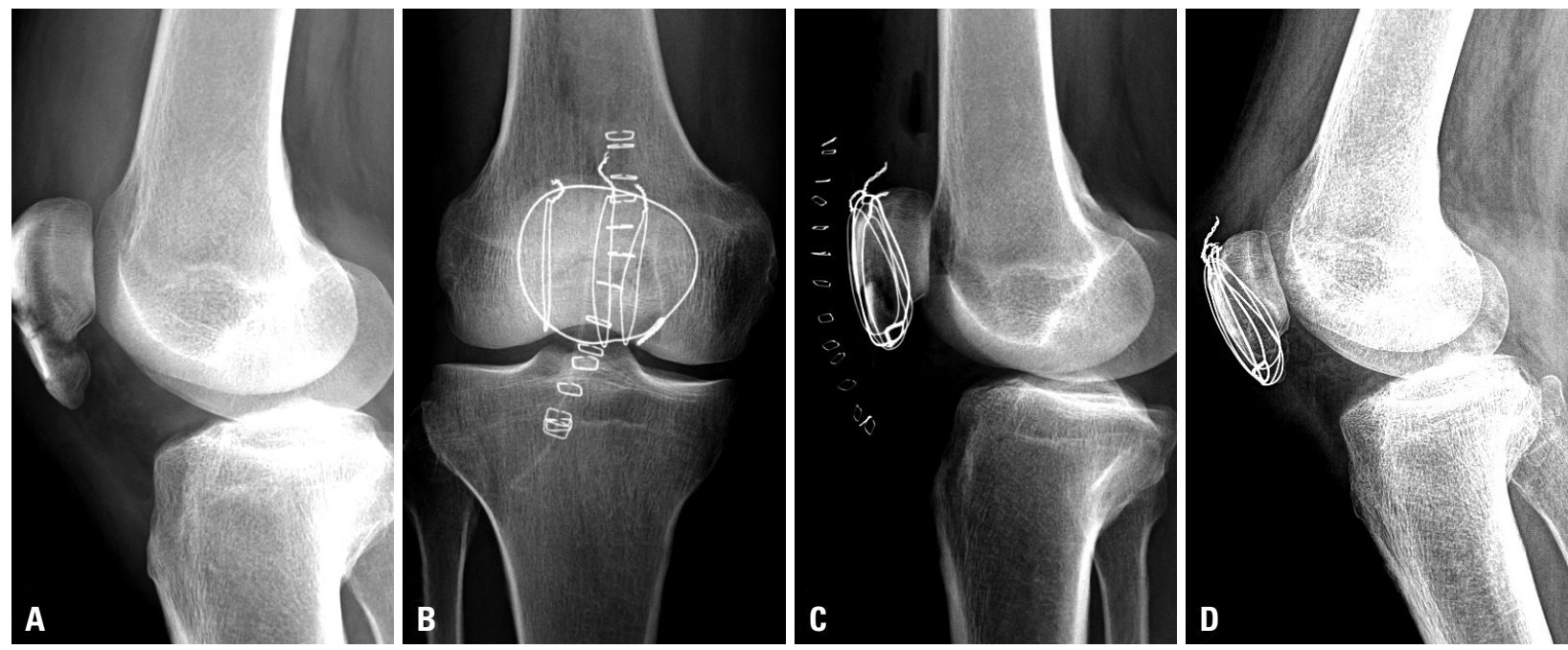

Fig. 4. Radiographs of a 70-year-old male patient. (A) Initial lateral radiograph showing displaced and comminuted fractures of the inferior pole of the patella. (B and C) Postoperative anteroposterior and lateral radiographs showing reduction of three comminuted fragments and fixation by three separate vertical wirings with cerclage wire. (D) Lateral radiograph at final check-up. 
removing the tension band wire she fell again, sustaining a fracture of the inferior pole of the patella. She was treated with the combined technique and recovered to the pre-fracture level.

\section{DISCUSSION}

We previously reported that separate vertical wiring is an effective method for treating comminuted fractures of the inferior pole of the patella. However, fixation failure did occur in some patients $>50$ years old after sudden contracture of the quadriceps muscle during unexpected falls. As demonstrated in the biomechanical experiment by Patel, et al., ${ }^{9}$ the force loaded to the quadriceps femoris muscle upon complete extension of the knee joint was $316 \mathrm{~N}$; however, separate vertical wiring alone provides an ultimate failure load on average of 216 in cadavers. Therefore, separate vertical wiring may not represent the best approach for achieving early active mobilization. Augmentation with cerclage wire was effective in that the ultimate load to failure increased according to the age of the specimens, whereby older patients demonstrated greater gain from the augmentation afforded by cerclage wiring. Moreover, all specimens demonstrated an ultimate load to failure of $\geq 250 \mathrm{~N}$ after augmentation with cerclage wiring, and most were closer to 300 N. Nonetheless, the protection from this combined technique may still not be good enough to prevent disruption of the fixation upon sudden contracture of the quadriceps during an unexpected fall, which is one of the reasons knee braces were applied to these patients. Although the holding power of this combined technique remains suboptimal, load to failure is acceptable for protected early ROM and quadriceps muscle exercise. Fortunately, we observed no loosening of the fixation after augmentation with cerclage wire in this series.

In cases of a simple fracture of the inferior pole of the patella, internal fixation is possible with either the modified tension band wiring technique or lag screw fixation. ${ }^{10,11}$ However, in comminuted fractures of the inferior pole of the patella, firm fixation that allows for early motion of the knee joint is difficult to obtain due to the inherent weakness of small bony fragments. For these cases, Chang and $\mathrm{Ji}^{5}$ reported a fixation technique using anterior tension band wiring through cannulated screws. The location of the comminuted fragments and cannulated screws offer no protection for the middle inferior part of the patel- la where the inferior pole fragments exist. Indeed, the average $17^{\circ}$ loss of knee flexion in half of the patients and the high incidence of weak knees may reflect insufficient fixation of this patella lower pole fracture. Previously, Kastelec and Veselko ${ }^{4}$ reported the results of basket plate fixation in comparision to partial patellectomy. Unfortunately, however, the basket plate is not available in many countries. Additionally, the mean age of patients experiencing inferior pole of the patella fractures has increased from 37 years (Yang and Byun) ${ }^{3}$ to 55 years (Kastelec and Veselko) $)^{4}$ to 60 years (Chang and Ji). ${ }^{5}$

Our study enrolled only patients who were over 50 years of age (mean 64.0 years). Older age implies weaker bones and may be associated with co-morbidities, such as impaired cognition from delirium, that impair early movement. Additionally, the patellofemoral joint reaction is proportional to both the degree of flexion of the knee joint and quardriceps muscle strength, reaching 0.5 -fold of the body weight while walking, 2.6-fold with the straight leg raise, and 7-fold when squatting. ${ }^{12}$ Even though augmentation with cerclage wiring provides initial stability in the operating room and allows approximately $90^{\circ}$ of knee flexion, a knee brace should be used for protection in the postoperative period. Despite increasing the average ultimate load to failure to $324.9 \mathrm{~N}$ with cerclage wire, wire breakage and/or wire segmentation remained significant disadvantages of this technique. In our study, breakage of the cerclage wire was observed in four patients. Since Biddau, et al. ${ }^{13}$ reported the migration of a broken cerclage wire from the patella to the heart, close follow-up must be undertaken for patients with broken wires and surgery should be offered when feasible.

Our study is limited by the lack of a control group (separate vertical wiring technique alone) in the clinical setting. However, we know from our previous study that the ultimate load to failure with the separate vertical wiring technique was not sufficient in patients older than 50 years. ${ }^{3}$ After introducing the combined technique, patients could increase the quadriceps muscle power and knee flexion even in the early postoperative period. Additionally, similar postoperative functional evaluation scores were achieved in this study, despite the older age of the patients.

Combining separate vertical wiring and cerclage wiring yields better fixation results than separate vertical wiring alone in patients over 50 years old. Augmentation of separate vertical wiring with cerclage wire in these patients provides enough strength for protected early exercise of the knee joint and uneventful healing. 


\section{REFERENCES}

1. Cramer KE, Moed BR. Patellar Fractures: Contemporary Approach to Treatment. J Am Acad Orthop Surg 1997;5:323-31.

2. Harris RM. Fractures of the patella and injuries to the extensor mechanism. In: Rockwood CA, Green DP, Bucholz RW, editors. Rockwood and Green's Fractures in adults. 6th ed. Philadelphia: Lippincott Williams \& Wilkins; 2006. p.1969-97.

3. Yang KH, Byun YS. Separate vertical wiring for the fixation of comminuted fractures of the inferior pole of the patella. J Bone Joint Surg Br 2003;85:1155-60.

4. Kastelec M, Veselko M. Inferior patellar pole avulsion fractures: osteosynthesis compared with pole resection. J Bone Joint Surg Am 2004;86-A:696-701.

5. Chang SM, Ji XL. Open reduction and internal fixation of displaced patella inferior pole fractures with anterior tension band wiring through cannulated screws. J Orthop Trauma 2011;25:366-70.

6. Curtis MJ. Internal fixation for fractures of the patella. A comparison of two methods. J Bone Joint Surg Br 1990;72:280-2.
7. Hung LK, Lee SY, Leung KS, Chan KM, Nicholl LA. Partial patellectomy for patellar fracture: tension band wiring and early mobilization. J Orthop Trauma 1993;7:252-60.

8. Böstman O, Kiviluoto O, Nirhamo J. Comminuted displaced fractures of the patella. Injury 1981;13:196-202.

9. Patel VR, Parks BG, Wang Y, Ebert FR, Jinnah RH. Fixation of patella fractures with braided polyester suture: a biomechanical study. Injury 2000;31:1-6.

10. Carpenter JE, Kasman R, Matthews LS. Fractures of the patella. Instr Course Lect 1994;43:97-108.

11. Carpenter JE, Kasman RA, Patel N, Lee ML, Goldstein SA. Biomechanical evaluation of current patella fracture fixation techniques. J Orthop Trauma 1997;11:351-6.

12. Nisell R. Mechanics of the knee. A study of joint and muscle load with clinical applications. Acta Orthop Scand Suppl 1985;216:142.

13. Biddau F, Fioriti M, Benelli G. Migration of a broken cerclage wire from the patella into the heart. A case report. J Bone Joint Surg Am 2006;88:2057-9. 